\title{
Molecular characterization of Fusarium globosum strains from South African maize and Japanese wheat
}

\author{
Lorraine M. Moses ${ }^{1,2}$, Walter F. O. Marasas ${ }^{1}$, Hester F. Vismer ${ }^{1}$, Lieschen de Vos $^{2}$, John P. \\ Rheeder $^{1}$, Robert H. Proctor ${ }^{3}$ and Brenda D. Wingfield ${ }^{2}$
}

(1) PROMEC Unit, Medical Research Council, PO Box 19070, Tygerberg, 7505, South Africa.

(2) Department of Genetics, Forestry and Agricultural Biotechnology Institute, University of Pretoria, Pretoria, 0002, South Africa.

(3) National Centre for Agricultural Utilization Research, USDA Agriculture Research Service, Peoria, IL, USA.

Lorraine M. Moses

Email: lorraine.moses@mrc.ac.za

\begin{abstract}
The fungus Fusarium globosum was first isolated from maize in South Africa and subsequently from wheat in Japan. Here, multiple analyses revealed that, despite morphological similarities, South African maize and Japanese wheat isolates of the fungus exhibit multiple differences. An amplified fragment length polymorphism-based similarity index for the two groups of isolates was only $45 \%$. Most maize isolates produced relatively high levels of fumonisins, whereas wheat isolates produced little or no fumonisins. The fumonisin biosynthetic gene FUM1 was detected in maize isolates by Southern blot analysis but not in the wheat isolates. In addition, most of the maize isolates produced sclerotia, and all of them produced large orange to dark purple sporodochia in carrot agar culture, whereas wheat isolates did not produce either structure. In contrast, individual isolates from both maize and wheat carried markers for both mating type idiomorphs, which indicates that the fungus may be homothallic. However, a sexual stage of $F$. globosum was not formed under standard self-fertilization conditions developed for other homothallic species of Fusarium. The inability to produce the sexual stage is consistent with the high similarity of 87$100 \%$ and $\mathrm{G}_{\mathrm{ST}}$ index of 1.72 for the maize isolates, which suggests that these isolates are undergoing asexual but not sexual reproduction. Together, the results suggest that the South African maize and Japanese wheat isolates of $F$. globosum are distinct populations and could be different species.
\end{abstract}

\section{Introduction}

Fusarium globosum Rheeder, Marasas and Nelson was first isolated from maize (Zea mays L.) samples harvested in the former Transkei region of South Africa [33] and subsequently from wheat (Triticum aestivum L. em. Thell.) culms in subtropical Japan [1]. This species is characterized by abundant globose microconidia produced singly or in botryose clusters on monophialides and polyphialides in aerial mycelium. Clavate to ellipsoidal microconidia also are produced on both types of phialides, as well as in chains and in false heads. Like other species of Fusarium in Section Liseola [47], F. globosum does not produce chlamydospores.

South African maize isolates of F. globosum can produce B-series analogues of fumonisin (FB) mycotoxins [43]. Fumonisins were first implicated in various animal diseases such as equine leukoencephalomalacia [24] and subsequently demonstrated to cause liver cancer in rodents [14, 
17] and pulmonary edema syndrome in pigs [35]. These mycotoxins also have been linked epidemiologically to esophageal cancer in both South Africa and China [10,41]. More recently, it has been proposed that fumonisins be considered a potential risk factor for birth defects, including human neural tube defects (NTD) in populations consuming fumonisin-contaminated maize. This is due to the interference of this mycotoxin with folic acid utilization via depletion of cellular sphingolipids required for normal functioning of the folate receptor $\alpha[25,26]$.

The fumonisin biosynthetic ( $F U M)$ gene cluster consists of 17 genes that are localized to a $42.5 \mathrm{~kb}$ region of chromosome 1 in $F$. verticillioides $[6,7,30]$. The roles of most of these genes have been confirmed by gene deletion analysis. Deletion of FUM1, FUM6 or FUM8 blocks accumulation of all known fumonisins, indicating that these genes are indispensable for fumonisin production [29, 30, 37]. Also, strains lacking FUM2 produced only fumonisin analogues (FB2 and FB4) that lack the C-10 hydroxyl group [32], and FUM3 deletion mutants produce only analogues (FB3 and FB4) that lack the C-5 hydroxyl group [8]. The individual deletions of the remaining FUM genes resulted in various effects and influences on fumonisin production [6-9, 30, 48], including no effects on fumonisin accumulation with the deletions of FUM15, FUM16, FUM17 or FUM18 [9, 30, 32].

The teleomorph of F. globosum has not been identified, and it is not known if this Fusarium is capable of sexual reproduction. The ability to reproduce sexually is an important feature as meiotic recombination can generate and maintain genotypic variation that could result in the re-assortment of genes that direct traits such as virulence or toxin production. In Fusarium and other filamentous ascomycetes, sexual reproduction is controlled by the mating type (MAT) locus [13, 45]. In heterothallic species, there are two functional MAT alleles, which are designated MAT1-1 and MAT1-2 in Fusarium [49]. These alleles are idiomorphic as they exhibit no significant sequence similarity with regard to DNA or encoded proteins but map to the same chromosomal position. In heterothallic Fusarium species, two haploid individuals must have different MAT alleles in order to be sexually compatible and to complete the sexual cycle. In homothallic species, on the other hand, individual haploid strains have both MAT-1 and MAT-2 idiomorphs, which can be closely linked or fused [44]. These individuals are self-fertile and can complete the sexual cycle with or without a mate.

There is little sequence data available for F. globosum. The GenBank database contains only 19 nucleotide sequences corresponding to 8 different genes from various $F$. globosum strains. Nine sequences are for the translation elongation factor- $1 \alpha$ gene $(T E F-1 \alpha)$ and exhibit a 99-100\% identity to one another. However, close scrutiny of these sequences and accession information indicates that six are not from F. globosum. GenBank accessions AF160285, AY337440 and AY337441 were derived from maize isolates of $F$. globosum from South Africa. Accession AM404137 was derived from strain ITEM 6013, which is listed as a F. globosum isolate from Kansas. However, ITEM 6013 is in fact a maize isolate from South Africa, i.e. ITEM $6013=\mathrm{KSU}$ 11555 = MRC 6647 ex holotype of F. globosum (Logrieco and Leslie, personal communication). Similarly, GenBank accessions AM404135 and AM404136 are sequences that were derived from strains ITEM 1590 and ITEM 1874, respectively. However, according to the ITEM database, these strains are Fusarium proliferatum, rather than F. globosum.

Finally, accessions DQ854859, DQ85460 and DQ854461 were derived from strains attributed to Spanish isolates of F. globosum [23]. However, these three sequences are $100 \%$ homologous to the TEF-1 $\alpha$ sequences for $F$. proliferatum strains ITEM 1590 and ITEM 1874, which strongly suggests that these three Spanish strains are probably F. proliferatum and not $F$. globosum. Databases containing incorrect data could result in much confusion with the incorrect identification of newly isolated strains. 
The main objectives of this study were to determine (1) the mating type and the sexual reproductive capability of the F. globosum isolates; (2) the genetic variation among these isolates, especially between the $F$. globosum strains isolated from the two host plants in the two geographical locations; and (3) the levels of fumonisin B analogues produced by F. globosum strains.

\section{Materials and methods}

\section{Fungal isolates}

Resuspended lyophilized culture material of $18 \mathrm{~F}$. globosum strains, 15 isolated from maize in South Africa and 3 strains isolated from wheat in Japan, was used for the phylogenetic analysis, fumonisin quantitation and MAT-typing (Table 1). These were the only known F. globosum strains identified from the specific hosts in the respective geographical locations. All isolates are preserved in the culture collection of the PROMEC Unit, Medical Research Council (MRC), South Africa. Five F. globosum strains were used in a Southern Blot analysis and included two maize isolates exholotype MRC 6647 (sclerotial-producing) and MRC 6657 (non-sclerotial), and the three wheat isolates MRC 7883, MRC 7884 and MRC 7885.

Table 1. Fumonisin B analogues produced by Fusarium globosum strains isolated from maize in South Africa and wheat in Japan.

\begin{tabular}{|c|c|c|c|c|c|}
\hline \multicolumn{2}{|c|}{ Fusarium globasum strains } & \multicolumn{4}{|c|}{ Maximum fumonisin levels $\left(\mathrm{mg} \mathrm{kg}^{-1}\right)$ for } \\
\hline MRC no. & Other no. & $\mathrm{FB}_{1}$ & $\mathrm{FB}_{2}$ & $\mathrm{FB}_{3}$ & Total FB \\
\hline \multicolumn{6}{|c|}{ Maize Isolates, South Africa } \\
\hline 6646 & & 50 & $\mathrm{ND}^{\mathrm{b}}$ & 3.9 & 54 \\
\hline $6647^{2}$ & CBS 428.97 & 32 & $\mathrm{ND}^{\mathrm{b}}$ & 1.9 & 33 \\
\hline 6648 & CBS 429.97 & 57 & $\mathrm{ND}^{\mathrm{b}}$ & 2.7 & 60 \\
\hline 6649 & & 121 & 0.6 & 5.9 & 128 \\
\hline 6650 & & 2 & $\mathrm{ND}^{\mathrm{b}}$ & $\mathrm{ND}^{\mathrm{b}}$ & 2.1 \\
\hline 6651 & & 117 & 0.6 & 5.7 & 123 \\
\hline 6652 & & 52 & 5.0 & 6.6 & 64 \\
\hline 6654 & & 10 & 05 & 1.3 & 12 \\
\hline 6655 & & 126 & 0.7 & 5.4 & 132 \\
\hline 6656 & & 159 & 0.9 & 6.8 & 167 \\
\hline 6657 & CBS 430.97 & 121 & 0.6 & 6.8 & 128 \\
\hline 6659 & & 83 & 0.4 & 4.1 & 88 \\
\hline 6660 & CBS 431.97 & 114 & 0.6 & 5.6 & 120 \\
\hline 6661 & & 6 & 0.7 & ND & 6.7 \\
\hline 6662 & & 5 & 0.4 & ND & 5.4 \\
\hline \multicolumn{6}{|c|}{ Wheat Isolates, Japan } \\
\hline 7883 & BBA 69017 & 12 & $\mathrm{ND}^{\mathrm{b}}$ & $\mathrm{ND}^{\mathrm{b}}$ & 12 \\
\hline 7884 & BBA 69018 & $\mathrm{ND}^{\mathrm{b}}$ & $\mathrm{ND}^{\mathrm{b}}$ & $\mathrm{ND}^{\mathrm{b}}$ & ND \\
\hline 7885 & BBA 69019 & 2.1 & $\mathrm{ND}^{\mathrm{b}}$ & $N^{b}$ & 2.1 \\
\hline
\end{tabular}

MRC6647 = ex holotype

${ }^{b} \mathrm{ND}=$ Not detected (level of detection $<0.01 \mu \mathrm{g} \mathrm{kg}^{-1}$ )

\section{DNA isolation}

Isolates used in the phylogenetic and MAT-typing studies were cultured by inoculating approximately $1 \mathrm{ml}$ of a spore suspension (typically 106-107 conidia) in $100 \mathrm{ml}$ of Malt Extract Broth (Difco) and incubated at $25^{\circ} \mathrm{C}$ for 14 days in the dark. The mycelia were harvested by filtration through Whatman No. 1 filter paper and stored at $-20^{\circ} \mathrm{C}$ until DNA extraction. Mycelia 
were ground to a fine powder in liquid nitrogen, and total genomic DNA was extracted with the NucleoSpin Plant L Extraction Kit (Macherey-Nagel, Germany) following the manufacturer's instructions. The five strains used in the Southern Blot analysis were grown in liquid GYEP medium ( $2 \%$ glucose, $0.3 \%$ yeast extract, and $1 \%$ peptone) [37], incubated for 3 days at $25^{\circ} \mathrm{C}$, and the mycelia were harvested by vacuum filtration. Genomic DNA was isolated from lyophilized harvested mycelium using the DNeasy Plant Mini Kit (Qiagen, Valencia, CA, USA) according to the manufacturer's specifications.

\section{PCR amplification of $M A T$ idiomorphs}

Mating-type idiomorphs MAT-1 and MAT-2 for the F. globosum isolates were identified with PCRbased assays using Gfmat1 and Gfmat2 primer sets, respectively, as described in Steenkamp et al. [39]. Positive PCR controls used were F. sacchari mating type tester strains MRC 6525 and MRC 6524 for the MAT-1 and MAT-2 amplification reactions, respectively. PCR products were electrophoresed to estimate size of fragments in a 1\% agarose gel along with a 100-bp marker (Promega), purified by using the Wizard SV Gel and PCR Clean-up System (Promega), and subsequently submitted for sequencing. The resulting DNA sequences were compared using the BLAST algorithm against MAT sequences present in the GenBank database.

\section{Self-fertilization}

The method as described by Bowden and Leslie [5] was used for inducing self-fertilization to determine the perithecial producing ability of potentially homothallic strains. Briefly, cultures were grown on carrot agar in 6-cm Petri dishes at $25^{\circ} \mathrm{C}$ in the dark. After 7 days, $1.5 \mathrm{ml}$ of $2.5 \%$ Tween 60 (Sigma) was applied to the culture and spread across the surface with a glass rod, with subsequent incubation of up to 8 weeks at $18^{\circ} \mathrm{C}$ as well as at $22^{\circ} \mathrm{C}$ with $12 \mathrm{~h}$ photoperiod.

A sclerotia-producing maize isolate (MRC 6647) was also crossed with a non-sclerotial maize isolate (MRC 6657) according to the method described by Klittich and Leslie [18], with the nonsclerotial cultures used as the male strain. The wheat isolates were crossed with each other and used as both male and female strains. All strains used as male parents were cultured on complete media slants and incubated for 7 days at $25^{\circ} \mathrm{C}$ under light. The conidia of each male culture were suspended in $3 \mathrm{ml} 2.5 \%$ Tween $60 ; 1.5 \mathrm{ml}$ aliquot was transferred to the female carrot agar cultures where it was spread across the surface with a glass rod and incubated under similar conditions as described with self-fertilization.

\section{Amplified Fragment Length Polymorphisms}

Amplified fragment length polymorphisms (AFLPs) were prepared according to the protocol of Vos et al. [46] with modifications as described by Zeller et al. [50]. Fusarium isolates F. subglutinans MRC 7828 and F. circinatum MRC 7870 were used as reference strains [12]. Four selective amplification reactions generated AFLP fingerprints by using combinations of IRDye ${ }^{\mathrm{TM}} 700$-labeled EcoRI primers with two base selection (Biolegio, Malden, The Netherlands) and unlabeled MseI primers with two base selection. The two base selective primer combinations for the 4 amplification reactions were (1) $E c o \mathrm{RI}+\mathrm{AA}$ and $M s e \mathrm{I}+\mathrm{AA}$, (2) $E c o \mathrm{RI}+\mathrm{AC}$ and $M s e \mathrm{I}+\mathrm{AA}$, (3) $E c o \mathrm{RI}+$ and $M s e \mathrm{I}+\mathrm{AC}$, and (4) $E c o \mathrm{RI}+\mathrm{AA}$ and $M s e \mathrm{I}+\mathrm{GA}$. PCR conditions were as follows: 13 cycles of $10 \mathrm{~s}$ at $94^{\circ} \mathrm{C}, 30 \mathrm{~s}$ at $65^{\circ} \mathrm{C}\left(\right.$ decreased $0.7^{\circ} \mathrm{C}$ per cycle) and $1 \mathrm{~min}$ at $72^{\circ} \mathrm{C}, 23$ cycles of $10 \mathrm{~s}$ at $94^{\circ} \mathrm{C}, 30 \mathrm{~s}$ at $56^{\circ} \mathrm{C}$ and $1 \mathrm{~min}$ (increase of $1 \mathrm{~s}$ per cycle) at $72^{\circ} \mathrm{C}$, and 1 cycle of $1 \mathrm{~min}$ at $72^{\circ} \mathrm{C}$. AFLP electrophoresis was performed on a model 4200 LI-COR ${ }^{\circledR}$ automated DNA sequencer as described by Myburg et al. [27]. Digital gel images obtained from the LI-COR ${ }^{\circledR}$ system were analyzed with the AFLP-Quanta Software according to the manufacturer's user manual. Polymorphic bands were scored as '-' indicating absence, ' + ' indicating presence of bands and '?' indicating 
missing/unknown data.

\section{Similarity analysis}

The Dice Coefficients, determined using the combined AFLP data sets, were conducted with NTSYSpc software program to determine genetic distance among the isolates.

The genotypic diversity of the isolates was calculated using the Stoddart and Taylor [40] formula.

The maximum value for $\mathrm{G}_{\mathrm{ST}}$ is the number of individuals in the population, which occurs when each individual in the sample has a different genotype. The phylogram was generated using distance analysis using the AFLP scores.

\section{Southern Blot analysis}

Oligonuclueotide primers used to generate probes for genes FUM1, FUM2, FUM8, FUM14, FUM19 and FUM21 are presented in Table 2. The PCR products used as templates to generate the probes were amplified from the isolated genomic DNA of F. globosum MRC 6647 (ex-holotype strain) following the protocol described by Proctor et al. [31]. The 32P-labeled hybridization probes were prepared with the Ready-to-Go kit (Amersham Biosciences).

Table 2. Oligonucleotides used to generate probes for Southern Blot analysis.

\begin{tabular}{|c|c|c|c|}
\hline FUM gene & Oligonucleotide number & Nucleotide Sequences $\left.\left(5^{\prime}-3\right)^{\prime}\right)$ & Predicted product size (bp) \\
\hline \multirow[t]{2}{*}{ FUMI } & rp32 & ACAAGTGTCCTTGGGGTCCAGG & 700 \\
\hline & rp33 & GATGCTCTTGGAAGTGGCCTACG & \\
\hline \multirow[t]{2}{*}{ FUMR } & rp2056 & CAGACGTCTCTTCTTGCCTGCT & 1,000 \\
\hline & гр2057 & GCYGCRCATTGTGGTATCGTAAGTC & \\
\hline \multirow[t]{2}{*}{ FUMS } & rp679 & CGTAGTAGGAATGAGAAGGATG & 800 \\
\hline & гр680 & GCAAGCTTTGTGGCTGATTGTC & \\
\hline \multirow[t]{2}{*}{ FUMI4 } & rp2059 & CARTCATSATAGAGGACGACACTG & 1,250 \\
\hline & тр2061 & CTCTTGAACTCATACTGCTGCAA & \\
\hline \multirow[t]{2}{*}{ FUMI9 } & rp1935 & GTCTCCCAACGCOCTGCCTATCT & 900 \\
\hline & rp1937 & GACAGCAGAACTAGGCTCATCGAGT & \\
\hline \multirow[t]{2}{*}{ FUM21 } & rp 1944 & GTAATGGCWCAAACCCTTGCAATCA & 900 \\
\hline & rp 1949 & GTCTGGRCGCAAAMGGCKGCATC & \\
\hline
\end{tabular}

The genomic DNA was digested with the restriction endonuclease HindIII, subjected to electrophoresis and transferred to a nylon membrane. Southern Blot analysis was carried using the protocol described by Proctor et al. [31].

\section{Fumonisin analysis}

All isolates were cultured on maize patties (30 patties per strain) consisting of $30 \mathrm{~g}$ of ground yellow maize kernels mixed with $30 \mathrm{ml}$ sterile $\mathrm{dH}_{2} \mathrm{O}$ placed in $90-\mathrm{mm}$ glass petri dishes and autoclaved at $121^{\circ} \mathrm{C}$ for $1 \mathrm{~h}$ on two consecutive days. Autoclaved patties were inoculated with $1 \mathrm{ml}$ of a spore suspension prepared from lyophilized cultures diluted 1:100 with $\mathrm{dH}_{2} \mathrm{O}$. Cultures were incubated in the dark at $25^{\circ} \mathrm{C}$ for 21 days, and then dried at $50^{\circ} \mathrm{C}$ for $24 \mathrm{~h}$, ground to a meal and stored at $4^{\circ} \mathrm{C}$ until analysis. 
Sample extracts from the cultures were prepared by the method of Sydenham et al. [42]. In brief, $100 \mathrm{ml} \mathrm{CH}{ }_{3} \mathrm{OH} / \mathrm{H}_{2} \mathrm{O}(3: 1 \mathrm{v} / \mathrm{v})$ was added to $5 \mathrm{~g}$ culture material from each strain and homogenized for 3 min using a Polytron homogenizer (Polytron PT300, Kinematika). Extracts were centrifuged at $4,000 \times \mathrm{g}$ for $10 \mathrm{~min}$ at $4^{\circ} \mathrm{C}$, filtered (Whatman No. 4), and the filtrate adjusted to $\mathrm{pH} 6.0$ with $1 \mathrm{M}$ $\mathrm{NaOH}$. Aliquots $(5 \mathrm{ml})$ of the resultant filtrates were purified on solid-phase extraction cartridges containing silica-based strong anion-exchange (SAX) media (Varian, Harbor City, CA). The fumonisins were selectively eluted with a $1 \%$ solution of $\mathrm{CH}_{3} \mathrm{COOH}$ in $\mathrm{CH}_{3} \mathrm{OH}$. The eluate was evaporated to dryness, in the form of a fine powdery residue around the vials, at $60^{\circ} \mathrm{C}$ under nitrogen. The residue was redissolved in $\mathrm{CH}_{3} \mathrm{OH}$ prior to injection.

Levels of fumonisin $\mathrm{B}_{1}\left(\mathrm{FB}_{1}\right)$, fumonisin $\mathrm{B}_{2}\left(\mathrm{FB}_{2}\right)$ and fumonisin $\mathrm{B}_{3}\left(\mathrm{FB}_{3}\right)$ were determined by using reverse-phase high pressure liquid chromatography (HPLC) coupled with fluorescence detection, as their o-phthaldialdehyde (OPA) derivatives. The HPLC was performed at a flow rate of $1 \mathrm{ml} / \mathrm{min}$ on a Luna C18 column (Phenomenex, Torrance, CA), and the mobile phase consisted of mixtures of $\mathrm{CH}_{3} \mathrm{OH} / 0.1 \mathrm{M} \mathrm{Na}_{2} \mathrm{~B}_{4} \mathrm{O}_{7} \cdot 10 \mathrm{H}_{2} \mathrm{O}(76: 24 \mathrm{v} / \mathrm{v})$. Fumonisin analogues were detected and quantified based on comparisons of retention times and peak area with standards [34].

\section{Results}

\section{Mating type analysis}

In PCR experiments, primer pair Gfmat1 amplified an approximately 250-bp fragment from the $F$. sacchari MAT1-1 tester strain MRC 6525, but not the MAT1-2 tester strain, and from all isolates of F. globosum analyzed. Likewise, primer pair Gfmat 2 amplified a fragment of approximately $800 \mathrm{bp}$ from the F. sacchari MAT1-2 tester strain MRC 6524, but not the MAT1-1 tester strain, and from all isolates of F. globosum examined. As expected, sequence analysis revealed that the Gfmat1 PCR product from all strains corresponded to the $\alpha$-domain of the MAT1-1-1 gene and that the Gfmat2 product included the HMG-domain of the MAT1-2-1 gene. Amplification of fragments of both the MAT1-1 and MAT1-2 idiomorphs from individual isolates of $F$. globosum indicates that this species has at least a portion of both idiomorphs and that it maybe homothallic.

\section{Self-fertilization}

Based on the results of the molecular mating type analysis, we attempted to induce the sexual cycle by self-fertilization of all $F$. globosum isolates using the carrot agar assay that has been used to induce self-fertilization in F. graminearum/Gibberella zeae, a well-characterized homothallic species of Fusarium. Carrot agar cultures were incubated at 18 and at $22^{\circ} \mathrm{C}$ for up to 8 week cycles, but none of the $18 \mathrm{~F}$. globosum isolates analyzed produced perithecia. However, 9 of the 15 maize isolates produced sclerotia (Fig. 1a-d), and all produced large masses of sporodochia (Fig. 1e, f) under these conditions. In contrast, none of the wheat isolates produced sclerotia or sporodochial masses in the carrot agar cultures.

\section{Similarity analysis of AFLP data sets}

AFLP bands (Fig. 2) were scored from amplification with four selective primer combination reactions. Dice Coefficients of the combined AFLP data sets used to determine genetic distance among the isolates resulted in the identification of two subgroups within $F$. globosum with a similarity of $45 \%$ (Fig. 3). A high Dice Coefficient of $87-100 \%$ was observed among the maize isolates. The $\mathrm{G}_{\mathrm{ST}}$ statistic was calculated to estimate the degree of genotypic diversity of the individual clades representing the different host origin. The $\mathrm{G}_{\mathrm{ST}}$ values obtained for the isolates of the individual maize and wheat clusters were 1.72 and 1, respectively. The low variability observed for the South African maize isolates suggests a clonal population. The results from the Japanese 

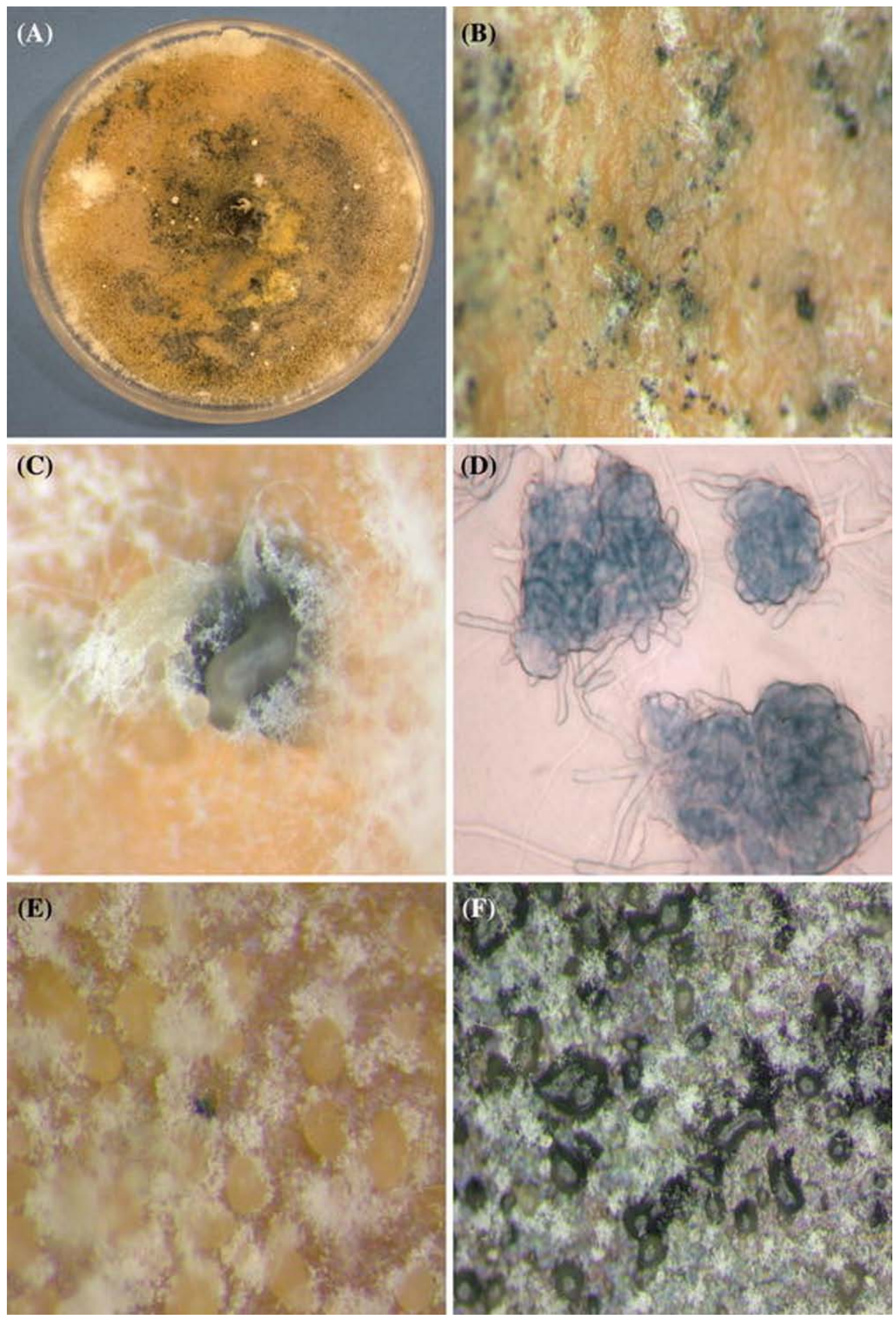
Figure 1. Sclerotia produced by maize isolates grown on carrot agar. a Fusarium globosum MRC 6647 (ex-holotype) at 4 weeks of incubation; b MRC 6647 culture with sclerotia produced on surface of carrot agar; c sclerotia with sporodochia produced by MRC 6649; d sclerotia under light microscope, $40 \times$ magnification. F. globosum cultures $(4 \times)$ showing large $\mathbf{e}-\mathbf{f}$ sporodochia on carrot agar after 4-8 weeks incubation. The dark sporodochia were observed on older cultures that produced more pigment with time

wheat isolates should be interpreted with caution as the isolate number is very low.

\section{Southern Blot analysis}

Southern Blot analysis was employed to determine the presence or absence of fumonisin biosynthetic genes FUM1, FUM2, FUM8, FUM14, FUM19 and FUM21 in the genomes of F. globosum strains from Japanese wheat and South African maize. These genes are distributed across the entire length of the fumonisin biosynthetic gene cluster and are required for fumonisin production in $F$. verticillioides [29, 30, 37]. Genomic DNA from five $F$. globosum strains was digested with HindIII, blotted and then hybridized to 32P-labeled probes for each of the six FUM genes. Hybridization signals were detected for FUM2, FUM8, FUM14, FUM19 and FUM21 in the South African maize and Japanese wheat isolates examined (Fig. 4). However, the hybridization signal for FUMI was detected only in the maize isolates (Fig. 4). In addition, there was differentiation in hybridization signal of FUM21 between the maize and wheat isolates.

\section{Fumonisin profiles}

The type and levels of the fumonisin $\mathrm{B}$ analogues produced by the F. globosum strains are summarized in Table $1 . \mathrm{FB}_{1}$ was detected in 17 of the 18 isolates, with the exception being the wheat isolate MRC 7884. The maize isolates were on average higher producers of $\mathrm{FB}_{1}$ with relatively low levels detected in the culture material of the wheat isolates. The maize isolates also produced moderate levels of $\mathrm{FB}_{2}$ and $\mathrm{FB}_{3}$, with $\mathrm{FB}_{3}$ on average being produced at higher levels. Nine of these strains produced both $\mathrm{FB}_{2}$ and $\mathrm{FB}_{3}$, three strains produced $\mathrm{FB}_{3}$ but not $\mathrm{FB}_{2}$, and two strains produced $\mathrm{FB}_{2}$ but were negative for $\mathrm{FB}_{3}$. MRC 6650 was the only maize isolate negative for both of these mycotoxins. None of the Japanese wheat isolates produced $\mathrm{FB}_{2}$ and $\mathrm{FB}_{3}$ in culture.

\section{Discussion}

Amplification of fragments of the MAT1-1 and MAT1-2 idiomorphs from F. globosum indicates that markers for both idiomorphs may be present in individual strains of this species, which suggest that both idiomorphs are present. If this is the case, $F$. globosum would be potentially homothallic. Homothallic species of Fusarium, such as F. graminearum/G. zeae, can produce ascospore-bearing perithecia in carrot agar cultures. However, multiple attempts to induce perithecial production in $F$. globosum under these conditions were not successful. Although the MAT locus controls mating in ascomycetes, other factors (e.g. temperature) may affect mating. In fact, strains of Fusarium oxysporum have MAT genes that can be transcribed [49], but sexual reproduction has not yet been observed in this species.

Genetic factors other than the MAT idiomorphs also can play a role in the ability of the fungus to reproduce sexually, and therefore account for the genetic variation among strains. A study by Shim et al. [38] demonstrated that FSR1 has a role in fungal virulence and sexual fertility in $F$. verticillioides and F. graminearum. FSRI encodes an 823-codon open reading frame interrupted by two introns, and the translated Fsr1 protein shares 60\% sequence homology with the Sordaria macrospora Pro11, a multimodular protein with a regulatory role in cell differentiation and ascocarp development. Fsrl mutants of $F$. verticillioides retained their male fertility but cannot function as a 


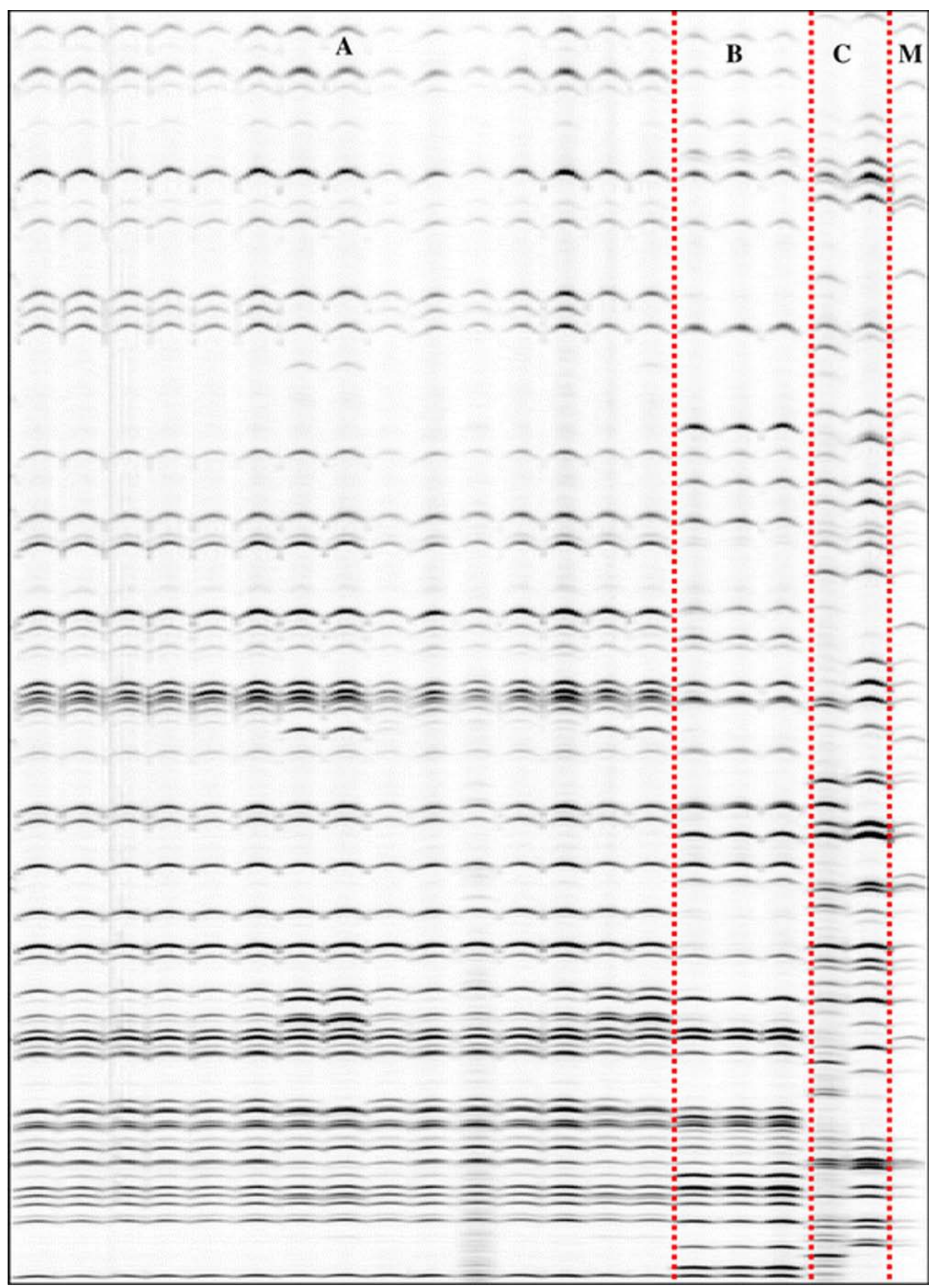

Figure 2. Li-Cor AFLP gel electrophoresis of selective amplification reactions using primer pair $E c o \mathrm{RI}+\mathrm{AC}$ and $M s e \mathrm{I}+\mathrm{AC}$. (A) 15 maize isolates; (B) 3 wheat isolates, (C) reference strains $F$. subglutinans MRC 7828 and F. circinatum MRC 7870, and (M) Marker. 


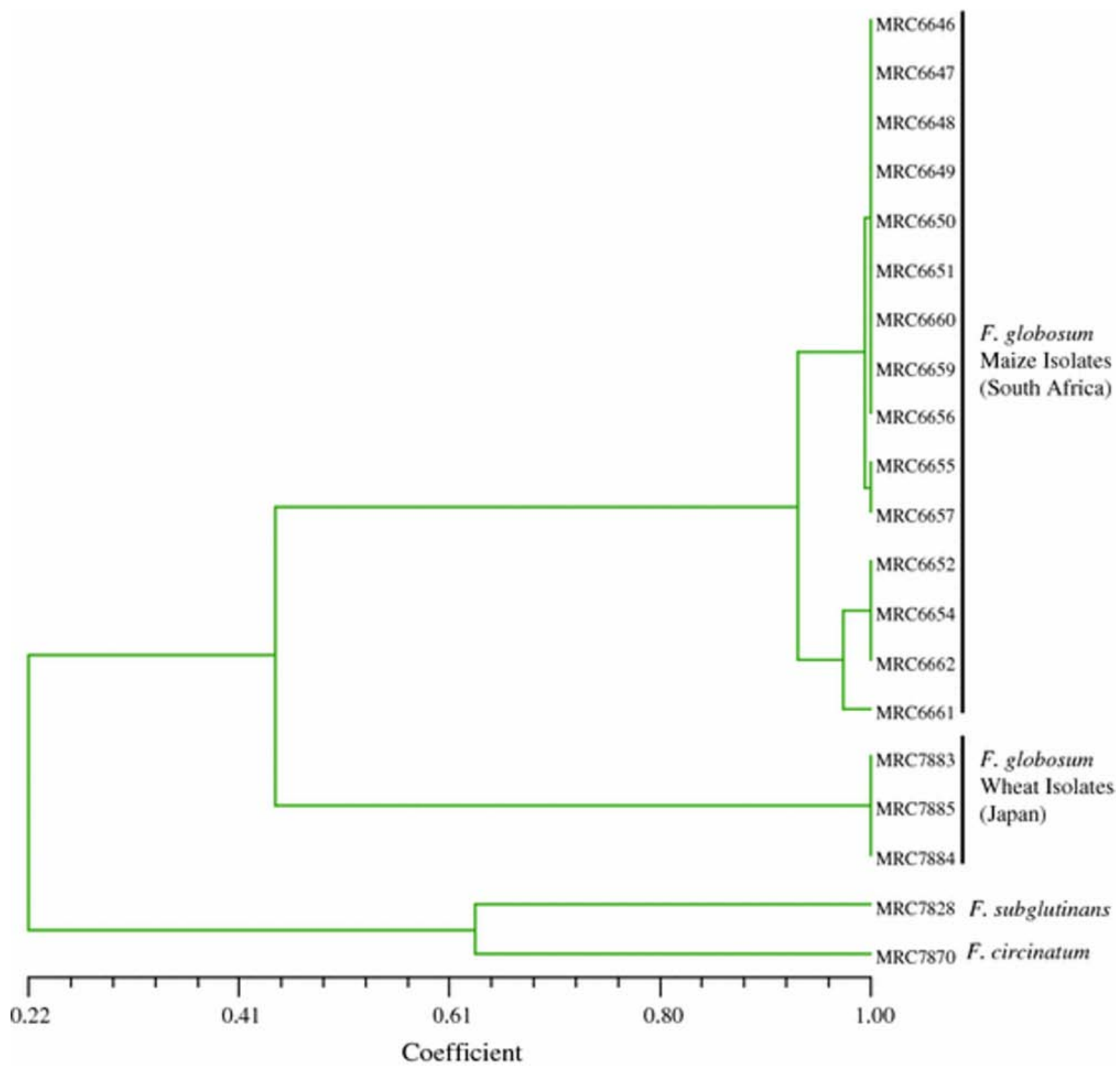

Figure 3. Genetic distance analyses of AFLP data matrix using the Dice Coefficient of Similarity for $F$. globosum strains isolated from maize and wheat with $F$. subglutinans MRC 7828 and $F$. circinatum MRC 7870 as reference strains.

female parent. Similarly, the disruption of FSR1 in the homothallic fungus, F. graminearum, resulted in a loss of self-fertility and perithecial development. These results suggested that Fsr1 protein appears to be critical in the mating of filamentous fungi by specifically controlling the development of female fertility.

Although $F$. globosum isolates did not form perithecia in carrot agar culture, most maize isolates of the fungus produced, sclerotia, compact masses of hardened mycelia. In ascomycetes, sclerotia serve as resting structures that allow fungi to survive adverse conditions such as drought, cold or heat. Sclerotia can be an indicator of female fertility in Fusarium. However, the production of such structures can vary widely within a species [21]. Sclerotia-like structures are frequently observed in cultures of sexually reproducing species such as $F$. verticillioides, $F$. proliferatum and $F$. sacchari, as well as with Fusarium species where no sexual stage has been identified, such as $F$. oxysporum and $F$. miscanthi. In carrot agar, maize isolates of $F$. globosum also formed large orange sporodochia that darkened with age. Such sporodochia were not reported in the original description of $F$. globosum [33]. However, this may reflect the fact that the original description of F. globosum utilized 


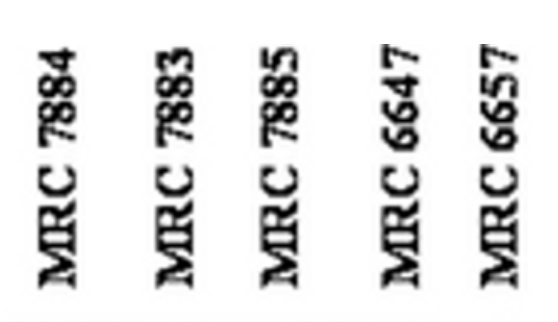

FUM1

FUM2

FUM8

FUM14

FUM19

FUM21 
Figure 4. The Southern Blot analysis was employed to determine the presence or absence of fumonisin biosynthetic genes FUM1, FUM2, FUM8, FUM14, FUM19 and FUM21 in the genomes of F. globosum strains from Japanese wheat (MRC 7883, MRC 7884, MRC 7885) and South African maize (MRC 6647, MRC6657). Hybridization signal was detected for FUM2, FUM8, FUM14, FUM19 and FUM21 in both the South African maize and Japanese wheat isolates examined, whereas the hybridization signal for $F U M 1$ was only detected in the maize isolates

carnation leaf agar (CLA) and potato dextrose agar (PDA), but not carrot agar.

AFLP analysis provided the opportunity to compare the genetic variability among the wheat and maize isolates, which exhibited morphological differences on carrot agar. The AFLP similarity analysis resolved the F. globosum isolates into two distinct clades; one clade corresponded to the Japanese wheat isolates and the other to the South African maize isolates. The Dice Coefficient of $45 \%$ observed between the two F. globosum strongly suggests that the wheat isolates from Japan are not $F$. globosum. It is possible that differences in the two populations of $F$. globosum may be related to their association with different hosts, but it is also possible that the differences between the populations resulted from their different geographical origins. However, because there are only three Japanese wheat isolates available, definitive statements about host and geographical specialization do not seem warranted when based on so few isolates.

O'Donnell et al. [28] investigated the phylogenetic relationships of the Gibberella fujikuroi complex, including F. globosum, using parsimony analyses performed on datasets of the 28S rDNA, mtSSU rDNA and $\beta$-tubulin gene sequences. All three Japanese wheat isolates and four South African maize isolates (viz. MRC 6647, MRC 6648, MRC 6657 and MRC 6660) were listed as strains included in the study. The analysis resolved $F$. globosum and other species such as $F$. fujikuroi, F. proliferatum and F. sacchari into a clade that O'Donnell et al. [28] designated as the Asian clade. However, sequences from multiple isolates were not reported in the analysis; instead, results from only one sequence per species (i.e. exemplar sequences) were reported. Thus, the analysis of O'Donnell et al. [28] did not reveal sequence variation within F. globosum. In the strict consensus trees based on the internal transcribed spacer (ITS) sequences (GenBank accession number U61687), only the Japanese wheat (Triticum) isolates were included in the analysis by O'Donnell et al. [28]. Also, the nucleotide sequences of 28S rDNA (U61661), mtSSU rDNA (U61609) and $\beta$-tubulin genes (U61583, U61557 and U61635) deposited in the GenBank database only lists a Japanese wheat isolate, viz MRC 7884 (NRRL 25190), as the organism used for sequencing. It is not clear whether different strains or a representative strain for each of the Fusarium species was used for analyses. The sequencing of a Japanese wheat isolate rather than the ex-holotype isolate from maize in South Africa, which is MRC 6647, as a representative strain could be the reason why F. globosum was grouped in the Asian clade. Alternatively, if both South African maize and Japanese wheat isolates were included in the analyses, it is possible that DNA sequence data provided insufficient resolution to distinguish between the closely related South African maize and Japanese wheat isolates. It was suggested that AFLPs be the method of choice for phylogenetic studies of closely related organisms when other characters (e.g. morphological characters) are identical $[3,16]$. An advantage of the AFLP procedure is the fact that the whole genome is used as the source of information for the banding patterns. This technique was first applied by Leissner et al. [19] to discriminate between strains of F. graminearum. AFLP has since proven to be a powerful tool for evaluating genetic variation in populations and has resolved many other questions concerning mating type and formae speciales in the genus Fusarium [2, 4, 11, 21, $22,36,51]$.

South African maize isolates and Japanese wheat isolates can also differ in conidial germination as Glenn [15] reported that conidial germ tubes of maize isolates MRC 6647 and MRC 6660 penetrated the surface of an agar medium, whereas germ tubes of Japanese wheat isolate MRC 7884 
(NRRL 25190) did not. These results further support the hypothesis that the maize and wheat isolates represent distinct populations.

The results obtained from the Southern Blot analysis also demonstrated dissimilarity between the South African maize isolates and the Japanese wheat isolates. The hybridization signal for $F U M 2$, FUM8, FUM14, FUM19 and FUM21 were detected in the genomes of all five F. globosum strains examined, which included two maize and three wheat isolates. In contrast, FUM1 was detected only in the maize isolates MRC 6647 (ex-holotype) and MRC 6657. A 290-bp FUM1 fragment was amplified from genomic DNA of all maize isolates, including the strains used in the Southern Blot analysis (data not shown). These FUM1 fragments were 100\% homologous and showed $72 \%$ homology to the FUM1 locus AF15573 (GenBank) of Gibberella moniliformis. These results indicate that in the Japanese wheat isolates, FUM1 is either absent or diverged markedly from the FUM1 orthologue in the South African maize isolate. This would be an obvious explanation for the dissimilarity in fumonisin profiles between the South African maize and the Japanese wheat isolates.

Most maize isolates produced $\mathrm{FB}_{1} \mathrm{FB}_{2}$ and $\mathrm{FB}_{3}$ analogues of fumonisins; a few isolates did not produce detectable levels of either $\mathrm{FB}_{2}$ or $\mathrm{FB}_{3}$, and MRC 6650 produced only $\mathrm{FB}_{1}$ at very low levels, similar to the wheat isolates, and very low levels of FB also were observed in MRC 6661 and MRC 6662. Generally, strains that produce fumonisins at 0 to $\sim 10 \mathrm{mg} / \mathrm{kg}$ are thought to have the same production profile, which would most likely be no or trace production. Genetic factors, specifically the $F U M$ genes, could result in the different fumonisin profiles observed between the different host isolates. Inactivation of FUM1, FUM6 or FUM8 blocks fumonisin production in $F$. verticillioides, which indicates these three genes are essential for fumonisin production [29, 37]. It is possible that one of these genes could have been inactivated or deleted in the fumonisin nonproducing wheat isolate MRC 7884. Similarly, strains lacking $\mathrm{FB}_{2}$ and/or $\mathrm{FB}_{3}$ could be lacking the activity of the FUM2 and/or FUM3 proteins, as FUM2 and FUM3 deletion mutants were shown to only produce $\mathrm{FB}_{2}$ and $\mathrm{FB}_{4}$, and $\mathrm{FB}_{3}$ and $\mathrm{FB}_{4}$, respectively $[8,32]$. The fumonisin $\mathrm{B}$ profiles where at least two different profiles were observed, support the other results in this study that the maize and wheat isolates are not the same species.

The AFLP analyses shed some insight into the reproductive mode of $F$. globosum. The Dice similarity index observed among the maize isolates is very high, which suggests that the maize isolates of $F$. globosum are clonal and reproduce by asexual rather than sexual cycle [20]. This is supported by the low index of genetic diversity $\left(\mathrm{G}_{\mathrm{ST}}\right)$ among the maize isolates. This low variability within these strains, and the association of each group with one host, would also be indicative of clonality, and therefore the lack of meiotic recombination which is the major source of variability. However, the possibility of sexual reproduction should not be ruled out, because sexual spores of a homothallic haploid fungus are identical to the parent and therefore would result in clonality. In order to devise effective strategies to control pathogen growth, to diminish fumonisin production in host plants, and thereby reduce the impact on human and animal health, knowledge of the genetic variability of mycotoxin-producing fungi is essential to be able to identify populations that are potentially toxigenic or shows differential host preferences.

In conclusion, isolates of $F$. globosum from South African maize and Japanese wheat differ in multiple traits. AFLP analysis indicates that the two groups of isolates represent genetically distinct populations that may be different species. Further research is needed to clarify this. The absence of perithecia coupled by the low genetic variability observed among the maize F. globosum strains implies that this Fusarium species is indeed an asexually reproducing fungus. 


\section{Acknowledgements}

Wheat isolates were kindly provided Dr T. Aoki, Department of Genetic Resources I, Ministry of Agriculture, Forestry and Fisheries, National Institute of Agrobiological Resources, Kannondai, 305-8602 Tsukuba, Ibaraki, Japan, and Dr H. I. Nirenberg, Biologische Bundesanstalt für Land- u. Forstwirtschaft, Institut für Mikrobiologie, Germany. We thank Marcie Moore for technical assistance with the Southern Blot analyses. Many thanks to the staff of the Forestry and Agricultural Biotechnology Institute, Faculty of Biological and Agricultural Sciences, University of Pretoria, Pretoria, South Africa, Martin Coetzee for assistance with the phylogenetic analyses. The authors also wish to thank Prof John Leslie, Department of Plant Pathology, Kansas State University, Manhattan, Kansas, USA, and Dr Antonio Logrieco, National Research Council, Institute of Sciences of Food Production, Via Amendola, Bari, Italy, for assisting in resolving the accurate identification of ITEM 6013.

\section{References}

1. Aoki T, Nirenberg H. Fusarium globosum from subtropical Japan and the effect of different light conditions on its conidiogenesis. Mycoscience. 1999;40:1-9.

2. Baayen RP, O’Donnell K, Bonants PJM, Cigelnik E, Kroon LPNM, Roebroeck EJA, Waalwijk C. Gene genealogies and AFLP analyses in the Fusarium oxysporum complex identify monophyletic and nonmonophyletic formae speciales causing wilt and rot disease. Phytopathology. 2000;90(8):891-900.

3. Bakkeren G, Krontstad JW, Lévesque CA. Comparison of AFLP fingerprints and ITS sequences as phylogenetic markers in Ustilaginomycetes. Mycologia. 2000;92(3): 510-21.

4. Boa JR, Fravel DR, O’Neill NR, Lazarovits G, van Berkum P. Genetic analysis of pathogenic and nonpathogenic Fusarium oxysporum from tomato plants. Can J Bot. 2002;80:271-9.

5. Bowden RL, Leslie JF. Nitrate non-utilizing mutants of Gibberella zeae (Fusarium graminearum) and their use in determining vegetative compatibility. Exp Mycol. 1992; 16:308-15.

6. Brown DW, Cheung F, Proctor RH, Butchko RAE, et al. Comparative analysis of 87000 expressed sequence tags from the fumonisin-producing fungus Fusarium verticillioides. Fungal Genet Biol. 2005;42:848-61.

7. Brown DW, Butchko RAE, Busman MA, Proctor RH. The Fusarium verticillioides FUM gene cluster encodes a $\mathrm{Zn}$ (II)2Cys6 protein that affects FUM gene expression and fumonisin production. Eukaryot Cell. 2007;6:1210-8.

8. Butchko RAE, Plattner RD, Proctor RH. FUM9 is required for C-5 hydroxylation of fumonisins and complements the meiotically defined Fum3 locus in Gibberella moniliformis. Appl Environ Microbiol. 2003;69:6935-7.

9. Butchko RAE, Plattner RD, Proctor RH. Deletion analysis of FUM genes involved in tricarballylic ester formation during fumonisin biosynthesis. J Agric Food Chem. 2006;54:9398404. 
10. Chu FS, Li GY. Simultaneous occurrence of fumonisin $B_{1}$ and other mycotoxins in moldy corn collected from the People's Republic of China in regions with high incidences of esophageal cancer. Appl Environ Microbiol. 1994;60(3): 847-52.

11. Chulze SN, Ramirez ML, Torres A, Leslie JF. Genetic variation in Fusarium section Liseola from no-till maize in Argentina. Appl Environ Microbiol. 2000;66(12):5312-5.

12. De Vos L, Myburg AA, Wingfield MJ, Desjardins AE, Gordon TR, Wingfield BD. Complete genetic linkage maps of an interspecific cross between Fusarium circinatum and Fusarium subglutinans. Fungal Genet Biol. 2007;44: 701-14.

13. Fincham JRS, Day PR, Radford A. Fungal genetics. 4th ed. Berkeley: University of California Press; 1979.

14. Gelderblom WCA, Kriek NPJ, Marasas WFO, Thiel PG. Toxicity and carcinogenicity of the Fusarium moniliforme metabolite, fumonisin $\mathrm{B}_{1}$, in rats. Carcinogenesis. 1991; 12:1247-51.

15. Glenn EA. Natural variation of ascospore and conidial germination by Fusarium verticillioides and other Fusarium species. Mycol Res. 2006;110:211-9.

16. Hodkinson TR, Renvoize SA, Chonghaile GN, Stapleton CMA, Chase MW. A comparison of ITS nuclear rDNA sequence data and AFLP markers for phylogenetic studies in Phyllostachys (Bambusoideae, Poaceae). J Plant Res. 2000;113:259-69.

17. Howard PC, Eppley RM, Stack ME, Warbritton A, Voss KA, Lorentzen RJ, Kovach RM, Bucci T. Fumonisin $\mathrm{B}_{1}$ carcinogenicity in two-year feeding study using F344 Rats and B6C3F1 mice. Environ Health Perspect. 2001;109: 277-82.

18. Klittich CJR, Leslie JF. Nitrate reduction mutants of Fusarium moniliforme (Gibberella fujikuroi). Genetics. 1988;118:417-23.

19. Leissner CEW, Niessen ML, Vogel RF. Use of the AFLP technique for the identification and discrimination of Fusarium graminearum. Cereal Res Commun. 1997;25: 555-6.

20. Leslie JF, Klein KK. Female fertility and mating type effects on effective population size and evolution in filamentous fungi. Genetics. 1996;144:557-67.

21. Leslie JF, Summerell BA. The Fusarium laboratory manual. Awes, Iowa: Blackwell Professional; 2006.

22. Leslie JF, Zeller KA, Lamprecht SC, Rheeder JP, Marasas WFO. Toxicity, pathogenicity and genetic differentiation of five species of Fusarium from sorghum and millet. Phytopathology. 2005;95(3):275-83.

23. Maciá-Vicente JG, Jansson H, Abdulla SK, Descals E, Salinas J, Lopez-Llorca JV. Fungal root endophytes from natural vegetation in Mediterranean environments with special reference to Fusarium spp. FEMS Microbiol Ecol. 2008;64:90-105.

24. Marasas WFO, Kellerman TS, Gelderblom WCA, Coetzer JAW, Thiel PG, Van Der Lugt JJ. Leukoencephalomalacia in a horse induced by fumonisin $\mathrm{B}_{1}$, isolated from Fusarium moniliforme. Onderstepoort J Vet Res. 1988;55: 197-203. 
25. Marasas WFO, Riley RT, Hendricks KA, Stevens VL, et al. Fumonisins disrupt sphingolipid metabolism, folate transport, and neural tube development in embryo culture and in vivo: a potential risk factor for human neural tube defects among populations consuming fumonisin-contaminated maize. J Nutr. 2004;134:711-6.

26. Missmer SA, Suarez L, Felkner M, Wang E, Merril AH, Rothman KJ, Hendricks KA. Exposure to fumonisins and the occurrence of neural tube defects along the Texas-Mexico Border. Environ Health Perspect. 2006;114: 237-41.

27. Myburg AA, Remington DL, O'Malley DM, Sedero RR, Whetten RW. High-throughput AFLP analysis using infrared dye-labeled primers and an automated DNA sequencer. BioTechniques. 2001;30:348-57.

28. O'Donnell KO, Cigelnik E, Nirenberg HI. Molecular systematics and phylogeography of the Gibberella fujikuroi species complex. Mycologia. 1998;90:465-93.

29. Proctor RH, Desjardins AE, Plattner RD, Hohn TM. A polyketide synthase gene required for biosynthesis of fumonisin mycotoxins in Gibberella fujikuroi mating population A. Fungal Genet Biol. 1999;27:100-12.

30. Proctor RH, Brown DW, Plattner RD, Desjardins AE. Co-expression of 15 contiguous genes delineates a fumonisin biosynthetic gene clusters in Gibberella moniliformis. Fungal Genet Biol. 2003;38:237-49.

31. Proctor RH, Plattner RD, Brown DW, Seo J-A, Lee Y-W. Discontinuous distribution of fumonisin biosynthetic genes in the Gibberella fujikuroi species complex. Mycol Res. 2004;108(7):815-22.

32. Proctor RH, Plattner RD, Desjardins AE, Busman M, Butchko RAE. Fumonisin production in the maize pathogen Fusarium verticillioides: genetic basis of naturally occurring chemical variation. J Agric Food Chem. 2006; 54:2424-30.

33. Rheeder JP, Marasas WFO, Nelson PE. Fusarium globosum, a new species from Corn in Southern Africa. Mycologia. 1996;88:509-13.

34. Rheeder JP, Marasas WFO, Vismer HF. Production of fumonisin analogues by Fusarium species. Appl Environ Microbiol. 2002;68:2101-5.

35. Ross PF, Nelson PE, Richard JL, Osweiler GD, Rice LG, Plattner RD, Wilson TM. Production of fumonisins by Fusarium moniliforme and Fusarium proliferatum isolates associated with equine leukoencephalomalacia and a pulmonary edema syndrome in swine. Appl Environ Microbiol. 1990;56:3225-6.

36. Schmidt H, Niessen L, Vogel RF. AFLP analysis of Fusarium species in the section Sporotrichiella - evidence for Fusarium langsethiae as a new species. Int J Food Microbiol. 2004;95:297-304.

37. Seo JA, Proctor RH, Plattner RD. Characterisation of four clustered and coregulated genes associated with fumonisin biosynthesis in Fusarium verticillioides. Fungal Genet Biol. 2001;34:155-65. 
38. Shim WB, Sagaram US, Choi YE, So J, Wilkinson HH, Lee YW. FSR1 is essential for virulence and female fertility in Fusarium verticillioides and F. graminearum. Mol Plant Microbe Interact. 2006;19:725-33.

39. Steenkamp ET, Wingfield BD, Coutinho TA, Zeller KA, Wingfield MJ, Marasas WFO, Leslie JF. PCR-based identification of MAT-1 and MAT-2 in the Gibberella fujikuroi species complex. Appl Environ Microbiol. 2000; 66(10):4378-82.

40. Stoddart JA, Taylor JF. Genotypic diversity: estimation and prediction in samples. Genetics. 1988;118:705-11.

41. Sydenham EW, Thiel PG, Marasas WFO, Shephard GS, Van Schalkwyk DJ, Koch KR. Natural occurrence of some Fusarium mycotoxins in corn from low and high esophageal cancer prevalence areas of the Transkei, Southern Africa. J Agric Food Chem. 1990;38:1900-3.

42. Sydenham EW, Shephard GS, Thiel PG, Stockenström S, van Schalkwyk DJ. Liquid chromatographic determination of fumonisins $\mathrm{B}_{1}, \mathrm{~B}_{2}$ and $\mathrm{B}_{3}$ in corn: AOAC-IUPAC collaborative study. J AOAC Int. 1996;79:688-96.

43. Sydenham EW, Shephard GS, Stockenström S, Rheeder JP, Marasas WFO, van der Merwe MJ. Production of fumonisin B analogues and related compounds by Fusarium globosum, a newly described species from corn. J Agric Food Chem. 1997;45:4004-10.

44. Turgeon BG. Application of mating type gene technology to problems in fungal biology. Annu Rev Phytopathol. 1998;136:115-37.

45. Turgeon BG, Yoder OC. Proposed nomenclature for mating type genes of filamentous ascomycetes. Fungal Genet Biol. 2000;31:1-5.

46. Vos P, Hogers R, Bleeker M, Reijans M, van de Lee T, Hornes M, Frijters A, Pot J, Peleman J, Kuiper M, Zabeau M. AFLP: a new technique for DNA fingerprinting. Nucleic Acids Res. 1995;23:4407-14.

47. Wollenweber HW, Reinking OA. Die fusarien. Berlin: Paul Parey; 1935.

48. Yi H, Bojja RS, Fu J, Du L. Direct evidence for the function of FUM13 I 3-ketoreduction of mycotoxins fumonisins in Fusarium verticillioides. J Agric Food Chem. 2005;53:5456-60.

49. Yun S-H, Arie T, Kaneko I, Yoder OC, Turgeon BG. Molecular organization of mating type loci in heterothallic, homothallic and asexual Gibberella/Fusarium species. Fungal Genet Biol. 2000;31:7-20.

50. Zeller KA, Jurgenson JE, El-Assiuty EM, Leslie JF. Isozyme and amplified fragment length polymorphisms from Cephalosporium maydis in Egypt. Phytoparasitica. 2000; 28:121-30.

51. Zeller KA, Summerell BA, Bullock S, Leslie JF. Gibberella konza (Fusarium konzum) sp. nov. from prairie grasses, a new species in the Gibberella fujikuroi species complex. Mycologia. 2003;95(5):943-54. 